\title{
EXPLORING NFC INTERACTIVE PANEL
}

\author{
Gustavo Ramírez-González \\ Universidad Carlos III de Madrid \\ Spain \\ gramirez@inv.it.uc3m.es
}

\author{
Mario Muñoz-Organero \\ Universidad Carlos III de Madrid \\ Spain \\ munozm@it.uc3m.es \\ Ángela Chantre Astaiza \\ Universidad Rey Juan Carlos-Spain \\ angela.chantre@gmail.com
}

\author{
Carlos Delgado Kloos \\ Universidad Carlos III de Madrid \\ Spain \\ cdk@it.uc3m.es
}

\begin{abstract}
This demo presents the design of the NFC Interactive Panel. This is a touchable surface with which mobile phones can interact. The surface represents a display for interactive and adaptive information controlled by people using NFC (Near Field Communication) enabled phones. The mobile phone is used to touch the surface selecting the different items displayed on it.
\end{abstract}

\section{Categories and Subject Descriptors}

H.5.2 [Information Interfaces and Presentation]: User Interfaces - Input devices and strategies.

\section{General Terms}

Design, Human Factors.

\section{Keywords}

NFC, panel, smart, interaction

\section{INTRODUCTION}

The NFC Interactive Panel is a collection of NFC tags placed in a flat surface (panel) that acts as a touchable screen. This panel shows different selectable options with which people can interact simply by touching on them. To enable this, the NFC Interactive Panel uses a mobile phone supporting Bluetooth and NFC [1]. NFC provides the touching capabilities and Bluetooth the communication with the projection system. NFC tags are set in the touchable surface and read via a J2ME application deployed on a mobile phone. This J2ME application connects to a controlling server (via Bluetooth) which interprets and

Permission to make digital or hard copies of all or part of this work for personal or classroom use is granted without fee provided that copies are not made or distributed for profit or commercial advantage and that copies bear this notice and the full citation on the first page. To copy otherwise, or republish, to post on servers or to redistribute to lists, requires prior specific permission and/or a fee.

MobiQuitous 2008, July 21 - 25, 2008, Dublin, Ireland.

Copyright (C) 2008 ICST ISBN 978-963-9799-27-1. displays the appropriate image on the surface according to the touching activity of the user.

\section{TECHNICAL DESIGN}

\subsection{General solution}

The basic infrastructure as is showed in figure 1, consist in a NFC mobile phone, a PC with a dongle Bluetooth and a projector. See figure 1 .

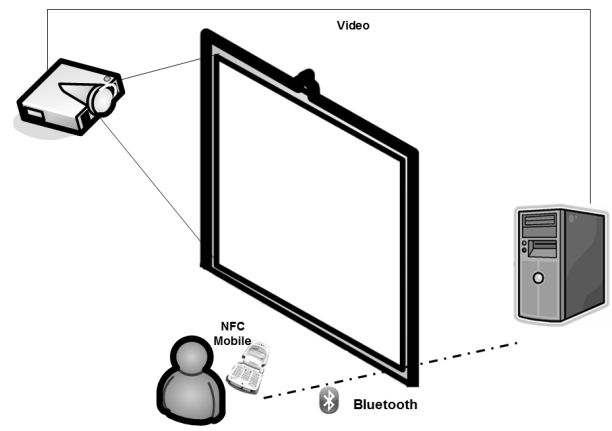

Figure 1. Basic infrastructure of NFC Interactive Panel.

The mobile phone contains a J2ME midlet application that search for the server. The name of the server also can be store previously. Once it's connected, user can touch any part of the panel and the place that is touched is send via Bluetooth to server which processes the touching as a click on screen. Actually to act as server, a Java enable application is used. To manage the Bluetooth connection is used BlueCove. [2]

\subsection{Building the Panel}

To build the Panel a set of NFC tags are placed in a flat piece. Some pictures of the building panel in figure 2 . 


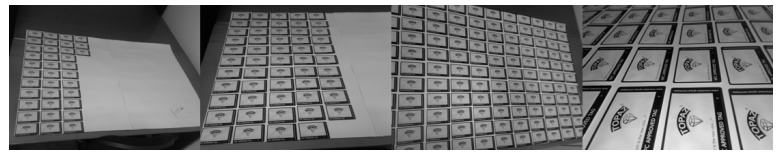

Figure 2. Building the panel.

This could be as small or large than is desired. Also personalize panels are possible according to the place where will be located. Tags used are TOPAZ Type 1 according to NFC Forum Tag Format [3].

\section{BASIC APPLICATIONS}

According to the context of the application, the touching activity could mean:

New Learning experiences (informal learning and mobile learning). The touch is the response to a game or an exploration for learning purpose. It can act as extension of whiteboard in classroom.

Advertising in public spaces for interaction with user. The touch means that user want to more information about a product offered or a place.

Information at Building. The touch means that user wants to more information about the place he is or products and services near that place.

In figure 3, some examples of the interaction are show. For some demo videos can be found in [4].

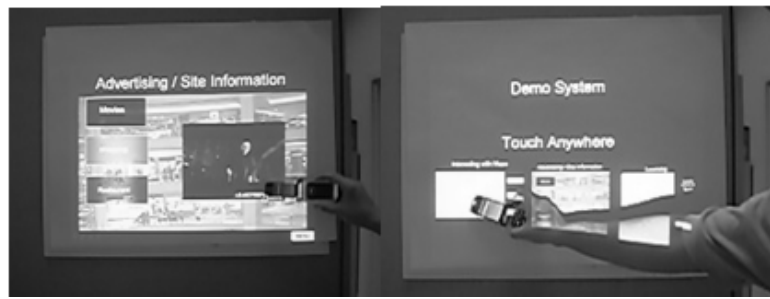

Figure 6. NFC Interactive Panel in action.

\section{INNOVATIVENESS OF THE APPROACH}

It is inspired in the concept of Surface computing proposed by Microsoft with its surface table. In surface, an expensive table has integrated sensors, processor and other staff to interact with finger. The next level it's to give this experience using a common device as is mobile phone. Also represent a next level in NFC because provides to Smart poster a new sense. A similar development can be found in [5], but limited to a specific application and a limited sized of display, the NFC Interactive Panel is independent from application and is adaptable to any size.

\subsection{Key differentiators}

As part of the principal innovations and advantages of NFC Interactive panel can be listed:

Less expensive than large plasma, kiosk or CRT displays.

Offer a new Learning experience. This concept could be extending as part of whiteboard solution in classroom or enabling mobile and informal learning.

High scalability because the panel could be as small or large as could be need.

Practically there isn't any problem on operation by dirt, rain or temperature.

Can interact with practically any PC application.

\section{ACKNOWLEDGMENTS}

This work was supported by the Spanish "Programa Nacional de Tecnologías de la Sociedad de la Información" through the projects TSI2005-08225-C07-01 and -02 . Gustavo Ramirez is funded by the EU Programme Alban, scholarship No. E06D101768CO and by University of Cauca.

Thanks to INNOVISION [3] for providing the tags for this demo.

\section{REFERENCES}

[1] NFC Forum. White Paper. The Keys to Truly Interoperable Communications. 2006

[2] Bluecove Google Code Group http://code.google.com/p/bluecove/

[3] TOPAZ Tags from INNOVISION. http://www.innovisiongroup.com/

[4] NFC Interactive Panel. Available video in . http://www.youtube.com/user/gusramir

[5] MULTITAG Project. http://eis.comp.lancs.ac.uk/multitag/ 